\title{
GENERALIZED NUMERICAL RADIUS AND RELATED INEQUALITIES
}

\section{T. BotTAZZI* AND C. CONDE}

Abstract. In [2], Abu Omar and Kittaneh defined a new generalization of the numerical radius. That is, given a norm $N(\cdot)$ on $\mathscr{B}(H)$, the space of bounded linear operators over a Hilbert space $H$, and $A \in \mathscr{B}(H)$

$$
w_{N}(A)=\sup _{\theta \in \mathbb{R}} N\left(\operatorname{Re}\left(e^{i \theta} A\right)\right) .
$$

They proved several properties and introduced some inequalities. We continue with the study of this generalized numerical radius and we develop diverse inequalities involving $w_{N}$. We also study particular cases when $N(\cdot)$ is the $p$ - Schatten norm with $p>1$.

Mathematics subject classification (2020): Primary 47A12, 47A30, 47A63; Secondary 47B10, 47B15, 51F20, 47B44. equality.

Keywords and phrases: Numerical radius, Schatten $p$-norm, orthogonality, norm-parallelism, in-

\section{REFERENCES}

[1] A. ABU-OMAR AND F. KitTANeh, Numerical radius inequalities for products of Hilbert space operators, J. Operator Theory 72 (2014), no. 2, 521-527.

[2] A. Abu-Omar And F. Kittaneh, A generalization of the numerical radius, Linear Algebra Appl. 569 (2019), 323-334.

[3] J. Alonso, H. Martini, AND S. Wu, On Birkhoff orthogonality and isosceles orthogonality in normed linear spaces, Aequationes Math. 83 (2012), 153-189.

[4] C. Benítez, M. Fernández And M. L. Soriano, Orthogonality of matrices, Linear Algebra Appl. 422 (2007), 155-163.

[5] R. Bhatia AND F. KitTANeh, Norm inequalities for partitioned operators and an application, Math. Ann. 287 (1990), no. 4, 719-726.

[6] R. Bhatia AND F. KitTANEH, On the singular values of a product of operators, SIAM J. Matrix Anal. Appl. 11 (1990), no. 2, 272-277.

[7] R. Bhatia And F. Kittaneh, Clarkson inequalities with several operators, Bull. London Math. Soc. 36 (2004), no. 6, 820-832.

[8] R. BHATIA AND P. ŠEMRL, Orthogonality of matrices and some distance problems, Linear Algebra Appl. 287 (1-3) (1999), 77-85.

[9] R. Bhatia AND X. Zhan, Compact operators whose real and imaginary parts are positive, Proc. Amer. Math. Soc. 129 (2001), 2277-2281.

[10] R. BHATIA AND X. ZHAN, Norm inequalities for operators with positive real part, J. Operator Theory 50 (2003), no. 1, 67-76.

[11] T. Bhattacharyya And P. GRover, Characterization of Birkhoff-James orthogonality, J. Math. Anal. Appl. 407 (2013), no. 2, 350-358.

[12] G. BIRKHOFF, Orthogonality in linear metric spaces, Duke Math. J. 1 (1935), 169-172.

[13] T. Bottazzi, C. Conde, M. S. Moslehian, P. Wójcik And A. Zamani, Orthogonality and parallelism of operators on various Banach spaces, J. Aust. Math. Soc. 106 (2019), no. 2, 160-183.

[14] M. L. BuZAno, Generalizzazione della diseguaglianza di Cauchy-Schwarz (Italian), Rend. Sem. Mat. Univ. e Politech. Torino 31 (1974), 405-409.

[15] M. FUJII AND F. KUbo, Buzano's inequality and bounds for roots of algebraic equations, Proc. Amer. Math. Soc. 117 (1993), no. 2, 359-361. 
[16] I. C. Gohberg AND M. G. KREǏN, Introduction to the theory of linear nonselfadjoint operators, Translated from the Russian by A. Feinstein. Translations of Mathematical Monographs, Vol. 18. American Mathematical Society, Providence, R. I., 1969.

[17] P. Grover, Orthogonality of matrices in the Ky Fan k-norms, Linear Multilinear Algebra 65 (2017), no. 3, 496-509.

[18] R. C. JAMES, Orthogonality in normed linear spaces, Duke Math. J. 12 (1945), 291-301.

[19] E. Kikianty AND S. S. Dragomir, Hermite-Hadamard's inequality and the p-HH-norm on the Cartesian product of two copies of a normed space, Math. Inequal. Appl. 13 (2010), no. 1, 1-32.

[20] F. KitTANEH, A numerical radius inequality and an estimate for the numerical radius of the Frobenius companion matrix, Studia Math. 158 (2003), no. 1, 11-17.

[21] F. KitTaneh, On zero-trace matrices, Linear Algebra Appl. 151 (1991), 119-124.

[22] F. KitTANEH, A note on the arithmetic-geometric-mean inequality for matrices, Linear Algebra Appl. 171 (1992), 1-8.

[23] F. Kittaneh, Norm inequalities for certain operator sums, J. Funct. Anal. 143 (1997), no. 2, 337348.

[24] Y. Li AND Y.-E. LI, Some characterizations of the trace norm triangle equality, Linear Algebra Appl. 484 (2015), 396-408.

[25] C.-K. Li AND H. SChneider, Orthogonality of matrices, Linear Algebra Appl. 347 (2002), 115122.

[26] B. Magajna, On the distance to finite-dimensional subspaces in operator algebras, J. London Math. Soc. (2) 47 (3) (1993), 516-532.

[27] C. A. MCCARThY, $c_{p}$, Israel J. Math., 5 (1967), 249-271.

[28] K. Paul, S. M. Hossein, K. C. Das, Orthogonality on $B(H, H)$ and minimal-norm operator, J. Anal. Appl. 6 (2008), no. 3, 169-178.

[29] K. PAUL, D. SAIN AND P. GHOSH, Birkhoff-James orthogonality and smoothness of bounded linear operators, Linear Algebra Appl. 506 (2016), 551-563.

[30] D. SAin, K. PAUl, AND S. Hait, Operator norm attainment and Birkhoff-James orthogonality, Linear Algebra Appl. 476 (2015), 85-97.

[31] A. SEDDIK, Rank one operators and norm of elementary operators, Linear Algebra Appl. 424 (2007), 177-183.

[32] J. G. STAMPFLI, The norm of a derivation, Pacific J. Math. 33 (1970), 737-747.

[33] T. YAMAZAKI, On upper and lower bounds for the numerical radius and an equality condition, Studia Math. 178 (2007), no. 1, 83-89.

[34] A. Zamani, The operator-valued parallelism, Linear Algebra Appl. 505 (2016), 282-295.

[35] A. Zamani And M. S. Moslehian, Exact and approximate operator parallelism, Canad. Math. Bull. 58 (1) (2015), 207-224.

[36] A. Zamani, M. S. Moslehian, Q. XU and C. FU, Numerical radius inequalities concerning with algebraic norms, arXiv: 1909.11438. 